\title{
Graphene-Based Composites as Cathode Materials for Lithium Ion Batteries
}

\author{
Libao Chen, ${ }^{1,2}$ Ming Zhang, ${ }^{2}$ and Weifeng Wei ${ }^{1}$ \\ ${ }^{1}$ State Key Laboratory for Powder Metallurgy, Central South University, Changsha 410083, China \\ ${ }^{2}$ Key Laboratory for Micro-Nano Optoelectronic Devices of Ministry of Education and State Key Laboratory for \\ Chemo/Biosensing and Chemometrics, Hunan University, Changsha 410082, China \\ Correspondence should be addressed to Weifeng Wei; weifengmit@gmail.com
}

Received 30 January 2013; Accepted 27 March 2013

Academic Editor: Yongzhu Fu

Copyright (C) 2013 Libao Chen et al. This is an open access article distributed under the Creative Commons Attribution License, which permits unrestricted use, distribution, and reproduction in any medium, provided the original work is properly cited.

Owing to the superior mechanical, thermal, and electrical properties, graphene was a perfect candidate to improve the performance of lithium ion batteries. Herein, we review the recent advances in graphene-based composites and their application as cathode materials for lithium ion batteries. We focus on the synthesis methods of graphene-based composites and the superior electrochemical performance of graphene-based composites as cathode materials for lithium ion batteries.

\section{Introduction}

Graphene is a free-standing 2D crystal with one-atom thickness of carbon atom. Those carbon atoms are $\mathrm{sp}^{2}$-hybridized atoms arranged in six-membered rings in a honeycombed network which is also considered as the fundamental foundation for fullerenes, carbon nanotubes, and graphite [1]. Graphene was discovered by Novoselov and coworkers in 2004 [2]. Owing to their great contribution for the study of graphene, Geim and Novoselov were awarded the Nobel Prize which was the third Nobel Prize in the field of carbon materials. As a kind of carbon materials, graphene has attracted increasing attention in a variety of fields because of its large specific surface area, good flexibility, superior chemical/thermal stability, and extraordinary electrical, and thermal, mechanical properties. With so many advantages, it is desirable to utilize the unique properties of graphene in composites through the incorporation with all kinds of functional materials [3-11]. One of the most important applications of graphene-based composites is electrode material for lithium ion batteries [12-15]. In this review, we focus on the synthesis methods and electrochemical performance of graphene-based composites as cathode materials for lithium ion batteries.

\section{LiMPO$_{4}(\mathrm{M}=\mathrm{Fe}, \mathrm{Co}, \mathrm{Mn}, \mathrm{V})$-Graphene Composites as Cathode Materials for LIBs}

$\mathrm{LiFePO}_{4}$ has been extensively investigated as cathode materials for LIBs because of low-cost, low toxicity, and relatively high theoretical specific capacity of $170 \mathrm{~mA} \mathrm{~h} / \mathrm{g}$. A significant restriction for $\mathrm{LiFePO}_{4}$ is its poor electronic conductivity (as low as $10^{-9} \mathrm{~S} \mathrm{~cm}^{-1}$ ) which exerts negative effects on the performance of LIBs. A concept of establishing a conducting network formed by carbonaceous materials has been proposed to improve the rete performance of electrode materials [16]. Graphene possessing high conductivity, chemical stability, and mechanical performance has been demonstrated to be excellent additive to improve the electrochemical performance of $\mathrm{LiFePO}_{4}$ as cathodes for LIBs. With the help of graphene, the electrons could be transferred easly between current collectors and the $\mathrm{LiFePO}_{4}$ particles, reducing the internal resistance of the batteries and enhancing the output power. On the other hand, the excellent mechanical properties of grapheme sheets are of benefit for the structure stability of electrode materials, resulting in an improved cyclic stability. Therefore, graphene sheets are beneficial to improve the properties of $\mathrm{LiFePO}_{4}$. The first publication about $\mathrm{LiFePO}_{4}$ graphene composites was finished by Ding and coworkers 
TABLE 1: Electrochemical performance of 3D $\mathrm{LiFePO}_{4}$-graphene composites in publications.

\begin{tabular}{|c|c|c|c|c|}
\hline \multirow{2}{*}{ Methods } & \multirow{2}{*}{ Cycling stability } & \multicolumn{2}{|c|}{ Rate capacity at $10 \mathrm{C}(\mathrm{mA} \mathrm{h} / \mathrm{g})$} & \multirow{2}{*}{ References } \\
\hline & & Composites & Without graphene & \\
\hline Sol-gel & $140 \%$ after 100 cycles & 60 & 45 & {$[21]$} \\
\hline Mechanical mixing & - & 109 & 75 & {$[22]$} \\
\hline Spray drying & $70 \%$ after 1000 cycles at $10 \mathrm{C}$ & 130 & 110 & [23] \\
\hline
\end{tabular}

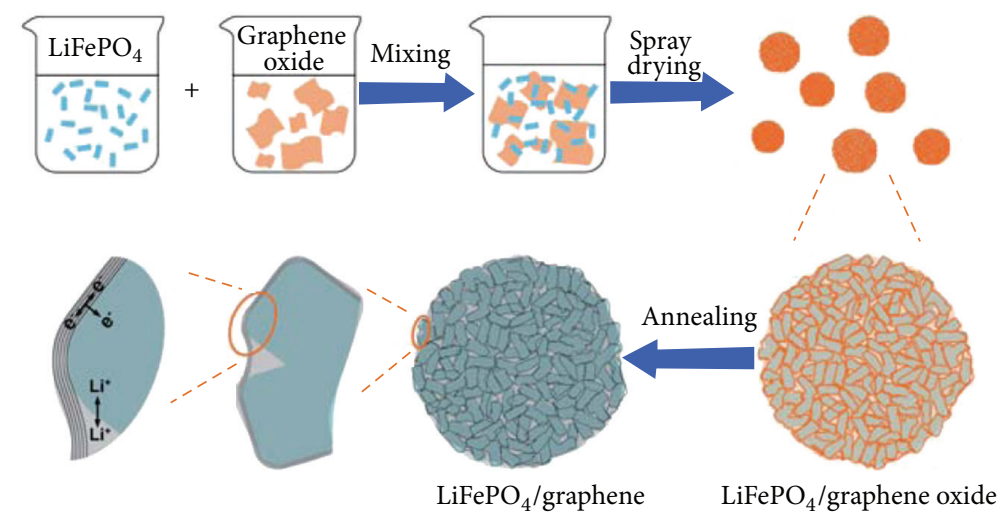

FIGURE 1: Illustration of the synthesis procedures and the microstructure of $\mathrm{LiFePO}_{4}$-graphene composites [23].

in 2010 [17]. The composites were prepared by a coprecipitation method, which delivered a specific capacity of $160 \mathrm{~mA} \mathrm{~h} / \mathrm{g}$ while there was only $113 \mathrm{~mA} \mathrm{~h} / \mathrm{g}$ for bare $\mathrm{LiFePO}_{4}$. $\mathrm{A}$ research carried out by $\mathrm{Su}$ and coworkers demonstrated that graphene sheets were powerful planar conductive additive to enhance the electrochemical performance of $\mathrm{LiFePO}_{4}$ [18]. The results showed that with a much lower fraction of graphene additive than those of commercial carbonbased agents, $\mathrm{LiFePO}_{4}$ displayed better charge/discharge performance than commercial cases. In a later study, $\mathrm{LiFePO}_{4}$-graphene composites were prepared through a facile hydrothermal route followed by hear treatment [19]. Except the liquid reaction, a solid-state route also was used to prepare $\mathrm{LiFePO}_{4}$-graphene composites [20]. The composites with a structure of scattering graphene sheets among $\mathrm{LiFePO}_{4}$ delivered a specific capacity of 161 and $70 \mathrm{~mA} \mathrm{~h} / \mathrm{g}$ at $0.1 \mathrm{C}$ and 50C.

To improve the electronic conductivity and transformation rate of $\mathrm{Li}^{+}, 3 \mathrm{D}$ porous $\mathrm{LiFePO}_{4}$-graphene composites were fabricated [21-23]. A case in point is that $3 \mathrm{D}$ hierarchical self-assembled $\mathrm{LiFePO}_{4}$-graphene composites were prepared by a facile template-free sol-gel method [21]. Another way to $3 \mathrm{D} \mathrm{LiFePO}_{4}$-graphene composites included the synthesis of 3D graphene networks by CVD and following mechanical mixing of graphene networks and $\mathrm{LiFePO}_{4}$ nanoparticles [22]. The electrochemical performance of the above two composites is shown in Table 1.

A more effective method to prepare $\mathrm{LiFePO}_{4}$-graphene composites with excellent performance was a spray-drying route [23]. This method is illustrated in Figure 1. $\mathrm{LiFePO}_{4}$ nanoparticles were wrapped by homogeneously and loosely graphene $3 \mathrm{D}$ networks to form $\mathrm{LiFePO}_{4}$-graphene composites with a microsized spherical secondary structure. The spherical secondary structure was of benefit for $\mathrm{Li}^{+}$diffusion, resulting in a high-specific capacity of $70 \mathrm{mAh} / \mathrm{g}$ at $60 \mathrm{C}$ discharge rate.

The electrochemical performance of $\mathrm{LiFePO}_{4}$ could be further improved by modifying it with both graphene sheets and carbon layers [36-40]. For example, LiFePO $@$ @graphene composites were prepared by a solvothermal route firstly. Then, the mixture of the above $\mathrm{LiFePO}_{4}$-graphene and citric acid was annealed at $873 \mathrm{~K}$ in $\mathrm{Ar} / \mathrm{H}_{2}$ to form $\mathrm{LiFePO}_{4} @ \mathrm{C}$ graphene composites [36]. Another similar route was employed to synthesis $\mathrm{LiFePO}_{4} @ \mathrm{C}$-graphene composites by using sucrose instead of citric acid [37]. Both of the above composites showed the specific capacity of $110 \mathrm{~mA} \mathrm{~h} / \mathrm{g}$ at a rate of $5 \mathrm{C}$. $\mathrm{LiFePO}_{4}$-graphene-C nanofibers also were fabricated by using a combination of electrospun and sol-gel techniques [38]. As cathode materials for LIBs, the composites possess high capacity, good cycling performances, and high rate capacity. A microwave-assisted hydrothermal method also was developed to synthesize $\mathrm{LiFePO}_{4} / \mathrm{C} /$ graphene composites with high efficiency and low cost [39].

$\mathrm{FePO}_{4}$ as a cathode material for LIBs also has drawn much attention recently. It can be prepared at low temperature and by a facile route. Besides, amorphous $\mathrm{FePO}_{4}$ exhibited continuous charge/discharge voltage profile. However, its conductance is unexpectedly lower than that of $\mathrm{LiFePO}_{4}$, resulting in its poor properties. To enhance the electrochemical performance of $\mathrm{FePO}_{4}, \mathrm{FePO}_{4}$-graphene composites were synthesized from an easy and simple chemical method [41]. The composites delivered a specific capacity of $156 \mathrm{~mA} \mathrm{~h} / \mathrm{g}$ after 100 cycles with a coulombic efficiency of nearly $100 \%$. At a large current density of $2.5 \mathrm{~A} / \mathrm{g}$, the capacity could retain at $100 \mathrm{~mA} \mathrm{~h} / \mathrm{g}$. In a later study, $\mathrm{FePO}_{4}$-graphene composites with hollow nanospheres were prepared by a hydrothermal method [42]. Those composites exhibited high rate capability and good cycle stability arising from the thin wall of 
the hollow nanospheres and fast electron transport through the graphene networks.

Compared to $\mathrm{LiFePO}_{4}, \mathrm{Li}_{3} \mathrm{~V}_{2}\left(\mathrm{PO}_{4}\right)_{3}$ is an attractive cathode material for LIBs, because its average extraction/ reinsertion voltage is about $4.0 \mathrm{~V}$, and its theoretical capacity is $197 \mathrm{~mA} \mathrm{~h} / \mathrm{g}$. Its intrinsic low electronic conductivity $(240 \mathrm{nS} / \mathrm{cm}$ at room temperature) limits its rate capacity. Although some approaches, such as doping by metal ions and carbon coating, have been employed to enhance its performance [43], graphene sheets seemed to be a more effective additive to improve its electrochemical performance. Liu and coworkers prepared $\mathrm{Li}_{3} \mathrm{~V}_{2}\left(\mathrm{PO}_{4}\right)_{3}$-graphene composites and investigated their electrochemical performances $[44,45]$. The composites prepared by a sol-gel route showed excellent rate capacity and cycling stability. The research also discovered that graphene was a more efficient carbon coating compared with the conventional carbon, which showed the advantages of graphene to improve the properties of $\mathrm{Li}_{3} \mathrm{~V}_{2}\left(\mathrm{PO}_{4}\right)_{3}$. Therefore, the rate capacities of $\mathrm{Li}_{3} \mathrm{~V}_{2}\left(\mathrm{PO}_{4}\right)_{3}$-graphene composites were much higher than those of bare $\mathrm{Li}_{3} \mathrm{~V}_{2}\left(\mathrm{PO}_{4}\right)_{3}$ and the hybrids of $\mathrm{Li}_{3} \mathrm{~V}_{2}\left(\mathrm{PO}_{4}\right)_{3}$ and conventional carbon. $\mathrm{Li}_{3} \mathrm{~V}_{2}\left(\mathrm{PO}_{4}\right)_{3} /$ graphene composites with 3D structure were synthesized by a spray-drying process [46]. The properties of $\mathrm{Li}_{3} \mathrm{~V}_{2}\left(\mathrm{PO}_{4}\right)_{3}$ could be improved further by coating the $\mathrm{Li}_{3} \mathrm{~V}_{2}\left(\mathrm{PO}_{4}\right)_{3}$ with a carbon layer. The composites could deliver a capacity of $131 \mathrm{~mA} \mathrm{~h} / \mathrm{g}$ at $10 \mathrm{C}$ after 100 cycles [47].

Compared to $\mathrm{LiFePO}_{4}, \mathrm{LiMnPO}_{4}$ is another attractive cathode for LIBs due to its higher $\mathrm{Li}^{+}$intercalation potential of $4.1 \mathrm{~V}$, resulting in about $20 \%$ higher energy density than that of $\mathrm{LiFePO}_{4}$. However, the electrical conductivity of $\mathrm{LiMnPO}_{4}$ is ultra low (lower than $\mathrm{LiFePO}_{4}$ by five orders of magnitude). Fe-doping of $\mathrm{LiMnPO}_{4}$ has been demonstrated to be an effective method to improve its performance [48]. But its performance still lies behind the demand of consumers. Therefore, $\mathrm{LiMn}_{1-x} \mathrm{Fe}_{x} \mathrm{PO}_{4}$-graphene composites were prepared to improve the electrochemical performances $[49,50] . \mathrm{LiMn}_{0.75} \mathrm{Fe}_{0.25} \mathrm{PO}_{4}$-graphene composites with high electrical conductivity and low ionic resistance led to excellent rate properties for the otherwise extremely insulating $\mathrm{LiMn}_{0.75} \mathrm{Fe}_{0.25} \mathrm{PO}_{4}$ cathodes. A further investigation showed that the interaction between $\mathrm{LiMn}_{0.75} \mathrm{Fe}_{0.25} \mathrm{PO}_{4}$ nanorods and graphene via charge redistribution not only anchored the nanorods onto the graphene sheets but also modified their surface chemistry, resulting in an ultra-high rate capacity as cathodes for LIBs [50].

The fundamental of using graphene to improve the properties of phosphate could be indexed to follow aspects. Firstly, graphene with high conductivity could enhance the conductance of electrode materials compared to unmodified phosphate. Secondly, the good mechanical property of graphene could maintain the microstructure of phosphate and improve the cyclic stability.

\section{Lithium Metal (Mn, Co, Ni) Oxide-Graphene Composites as Cathode Materials for LIBs}

$\mathrm{LiMn}_{2} \mathrm{O}_{4}$ with advantages of low cost, environmental friendliness, and high abundance has drawn much attention in recent years [51]. Its low electrical conductivity resulted in a low-rate capacity. Published papers have demonstrated that graphene sheets were effective agents to improve their conductivity and rate capacity. $\mathrm{LiMn}_{2} \mathrm{O}_{4}$-graphene composites with high rate capacity were synthesized by a microwaveassisted hydrothermal method [52]. The composites exhibited reversible capacities of 117 and $101 \mathrm{~mA} \mathrm{~h} / \mathrm{g}$ at $50 \mathrm{C}$ and $100 \mathrm{C}$. In another study, $\mathrm{LiMn}_{2} \mathrm{O}_{4}$-graphene composites were synthesized by self-assembly approach combined with a solid-state lithiation method [53]. The enhancement in electrochemical properties could be attributed to the superior $\mathrm{Li}^{+}$diffusion kinetics and improved stability across a wide voltage window in crystalline $\mathrm{LiMn}_{2} \mathrm{O}_{4}$-graphene composites. Especially, their capacities approached the theoretical value, and the cycling stability was enhanced.

$\mathrm{LiNi}_{1 / 3} \mathrm{Mn}_{1 / 3} \mathrm{Co}_{1 / 3} \mathrm{O}_{2}$ as a promising candidate for $\mathrm{LiCoO}_{2}$ has attracted a lot of interest [54]. It shows a high energy density, good stability, enhanced safety, and low cost. However, the cation disorder occurred during calcination results in the deterioration in the kinetic property. To enhance its electrochemical performance, $\mathrm{LiNi}_{1 / 3} \mathrm{Mn}_{1 / 3} \mathrm{Co}_{1 / 3} \mathrm{O}_{2}$-graphene composites were prepared as cathodes for LIBs. It was reported by Jiang and coworkers that $\mathrm{LiNi}_{1 / 3} \mathrm{Mn}_{1 / 3} \mathrm{Co}_{1 / 3} \mathrm{O}_{2}$-graphene composites prepared by mechanical mixing could deliver a capacity of $115 \mathrm{~mA} \mathrm{~h} / \mathrm{g}$ at $6 \mathrm{C}$ [55]. $\mathrm{LiNi}_{1 / 3} \mathrm{Mn}_{1 / 3} \mathrm{Co}_{1 / 3} \mathrm{O}_{2}$-graphene composites prepared by microemulsion and ball-milling route could deliver a reversible capacity of $150 \mathrm{~mA} \mathrm{~h} / \mathrm{g}$ at a rate of $5 \mathrm{C}$, much higher than that of bare $\mathrm{LiNi}_{1 / 3} \mathrm{Mn}_{1 / 3} \mathrm{Co}_{1 / 3} \mathrm{O}_{2}$ [56]. The improved performance was attributed to the grain connectivity and high electronic conductivity. $\mathrm{LiNi}_{0.8} \mathrm{Co}_{0.15} \mathrm{Al}_{0.05} \mathrm{O}_{2}$ graphene also was prepared by a high mechanical ball-milling method. They exhibited the high capacity of $180 \mathrm{~mA} \mathrm{~h} / \mathrm{g}$ with good cycle stability [57].

\section{Sulfur-Graphene Composites as Cathode Materials for LIBs}

The lower specific capacities of cathode materials (about $150 \mathrm{~mA} \mathrm{~h} / \mathrm{g}$ for layered oxides and $170 \mathrm{~mA} \mathrm{~h} / \mathrm{g}$ for $\mathrm{LiFePO}_{4}$ ) compared to those of anodes $(370 \mathrm{~mA} \mathrm{~h} / \mathrm{g}$ for graphene and $993 \mathrm{~mA} \mathrm{~h} / \mathrm{g}$ for tin) have been a limiting factor to improve the energy density of LIBs. As a cathode for LIBs, sulfur possesses a theoretical specific capacity of $1675 \mathrm{~mA} \mathrm{~h} / \mathrm{g}$ which is about five times higher than those of traditional cathode materials [58]. Its disadvantages of the low electrical conductivity and dissolution of polysulfides in electrolyte also are obvious. Sulfur-graphene composite has been demonstrated to be one way to improve the electrochemical performance of sulfur in LIBs.

The first report about S-graphene composite as cathode for LIBs was available online in October of 2010, which was completed by Wang and coworkers [24]. The composites, prepared by the heat treatment of the mixture of graphene sheets and elemental sulfur, exhibited a specific capacity of $600 \mathrm{~mA} \mathrm{~h} / \mathrm{g}$ after 40 cycles at a current density of $50 \mathrm{~mA} / \mathrm{g}$. An improved method of preparing S-graphene 
TABLE 2: Electrochemical performance of S-graphene composites in the literatures.

\begin{tabular}{|c|c|c|c|}
\hline Structure & Method & Capacity & References \\
\hline Graphene coated by S particles & Heat mixing & $400 \mathrm{~mA} \mathrm{~h} / \mathrm{g}$ after 40 cycles & {$[24]$} \\
\hline Sandwich-type & Solution-mixing & $505 \mathrm{~mA} \mathrm{~h} / \mathrm{g}$ after 100 cycles & {$[25]$} \\
\hline S particles wrapped by graphene & Self-assembly & $600 \mathrm{~mA} \mathrm{~h} / \mathrm{g}$ after 100 cycles & {$[26]$} \\
\hline$S$ particles in graphene & Oil/water system & $620 \mathrm{~mA} \mathrm{~h} / \mathrm{g}$ after 60 cycles at $1 \mathrm{C}$ & [27] \\
\hline- & Deposition from $\mathrm{Na}_{2} \mathrm{~S}_{x}$ & $950 \mathrm{~mA} \mathrm{~h} / \mathrm{g}$ after 55 cycles & {$[28]$} \\
\hline Wrinkled laminar structure & Deposition from $\mathrm{Na}_{2} \mathrm{~S}_{2} \mathrm{O}_{3}$ & $667 \mathrm{~mA} \mathrm{~h} / \mathrm{g}$ after 200 cycles & [29] \\
\hline S particles in graphene sheets & Deposition from $\mathrm{Na}_{2} \mathrm{~S}_{2} \mathrm{O}_{3}$ & $830 \mathrm{~mA} \mathrm{~h} / \mathrm{g}$ after 50 cycles & {$[30]$} \\
\hline$S$ in the pores of actived graphene & Melt-diffusion & $1000 \mathrm{~mA} \mathrm{~h} / \mathrm{g}$ after 60 cycles at $0.2 \mathrm{C}$ & {$[31]$} \\
\hline S particles on graphene & Melting diffusion & $957 \mathrm{~mA} \mathrm{~h} / \mathrm{g}$ after 50 cycles & {$[32]$} \\
\hline Ternary composites & In situ polymerization & $560 \mathrm{~mA} \mathrm{~h} / \mathrm{g}$ after 100 cycles & {$[33]$} \\
\hline Sandwich-type & Heat mixing & $800 \mathrm{~mA} \mathrm{~h} / \mathrm{g}$ after 100 cycles & {$[34]$} \\
\hline $\mathrm{S}$ in the porous graphene & Melt-diffusion & $755 \mathrm{~mA} \mathrm{~h} / \mathrm{g}$ at $0.1 \mathrm{C}$ & {$[35]$} \\
\hline
\end{tabular}

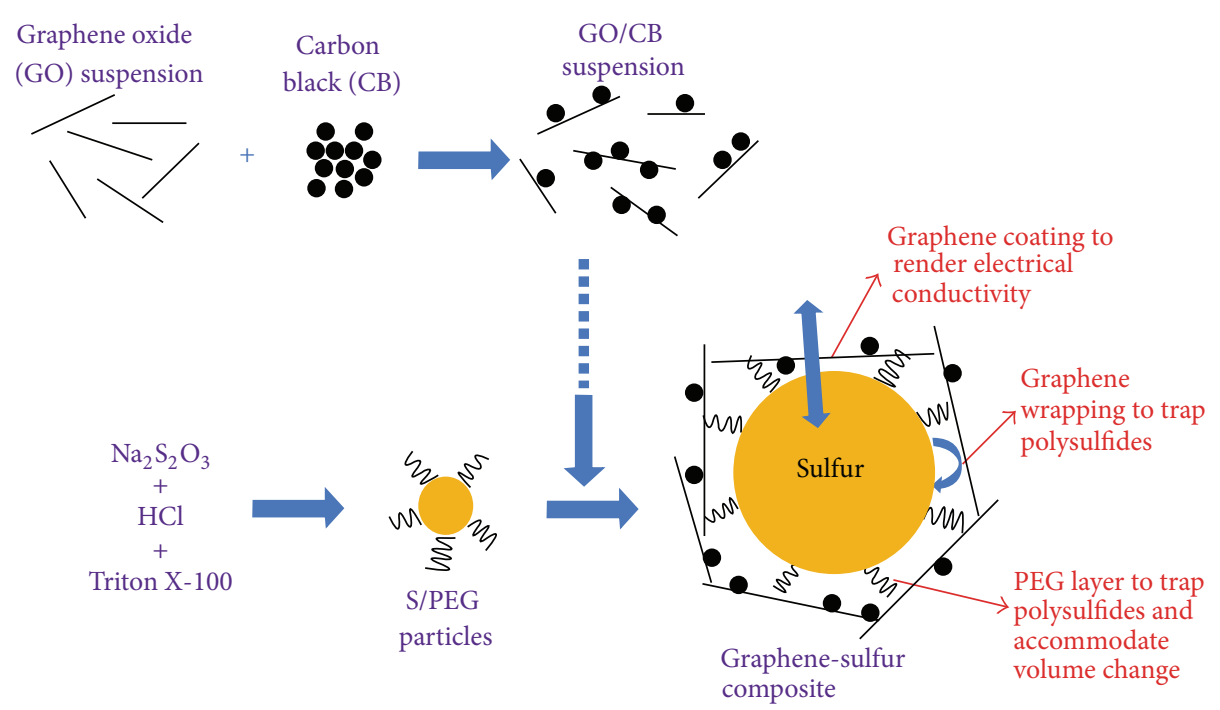

FIGURE 2: Illustration of the synthesis procedures for S-graphene composites and a proposed schematic structure of the composite [26].

by mixing graphene with the solution of sulfur was developed by Cao and coworkers [25]. The composites with a sandwich structure could deliver a specific capacity of $750 \mathrm{~mA} \mathrm{~h} / \mathrm{g}$ after 50 cycles at a current density of $168 \mathrm{~mA} / \mathrm{g}$. To further improve the electrochemical performance, S-graphene composites with a wrapped structure were synthesized [26]. Improved performance was achieved by the graphenewrapped composites which could be attributed to sulfur particles of well coated and confined by graphene sheets and meanwhile integrated polymeric cushions in composites. The synthesis method and the microstructure of composites were illustrated in Figure 2. An oil/water system also could be employed to prepare sulfur/graphene with a core/shell structure [27].

To modify the interface between graphene and sulfur, sulfur was anchored on graphene sheets by using $\mathrm{Na}_{2} \mathrm{~S}_{x}$ as sulfur sources [28]. Graphene sheets were coated by a uniform and thin sulfur to form S-graphene composites. A similar method by employing $\mathrm{Na}_{2} \mathrm{~S}_{2} \mathrm{O}_{3}$ as sulfur source also was used to prepare S-graphene composites [29]. To improve the electrochemical performance of S-graphene composites, graphene was treated by HF to eliminate impurities and create active sites for the nucleation of sulfur particles on graphene sheets [30]. The composites showed a specific capacity of $830 \mathrm{~mA} \mathrm{~h} / \mathrm{g}$ after 50 cycles at a current density of $168 \mathrm{~mA} / \mathrm{g}$, much higher than that of S-carbon composites. Another active method for graphene is based on the thermal process with $\mathrm{KOH}$ [31].

S-graphene composites with a layer-by-layer structure were synthesized by melt-diffusion strategy [32]. A dwindled over-discharged phenomenon and excellent rate capability were achieved by the composites. To avoid the dissolution of polysulfides and improve the performance of composites, polyacrylonitrile-sulfur-graphene composites were prepared by an in situ polymerization approach [33]. Table 2 shows some results about S-graphene composites as cathodes for LIBs. The improved performance of S-graphene composites could be ascribed to graphene sheets, which acted as conductive agent to enhance conductivity and protective layer to block the diffusion of polysulfides. 


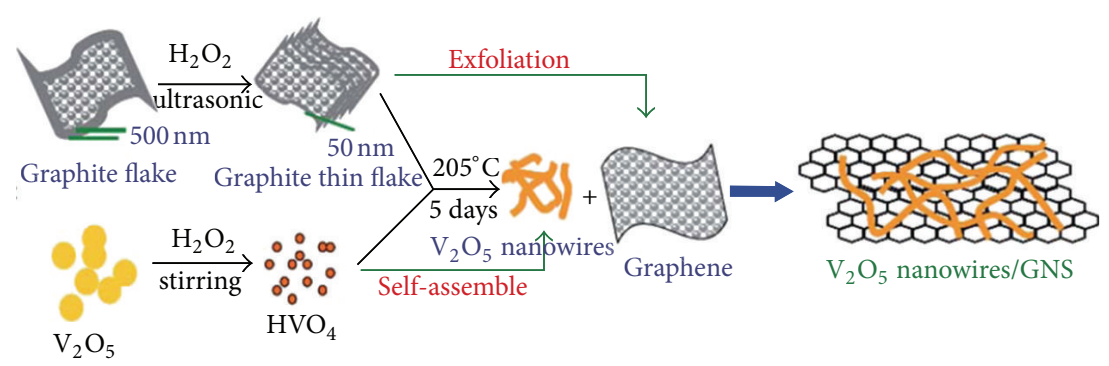

(a)

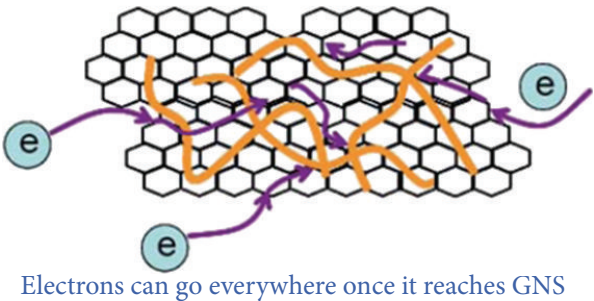

(b)

Figure 3: (a) Illustration of the synthesis route of $\mathrm{V}_{2} \mathrm{O}_{5}$-graphene composites. (b) Ideal electron transfer pathway for $\mathrm{V}_{2} \mathrm{O}_{5}$-graphene composites [60].

The enhancement of S-graphene as cathodes for LIBs could be ascribed to the following reasons. Firstly, grapheme sheets as good electronic conductors could enhance the conductance of sulfur-based materials. Secondly, the layered graphene sheets with good sealability could prevent the loss of polysulfides.

\section{Metal Oxide-Graphene Composites as Cathode Materials for LIBs}

$\mathrm{V}_{2} \mathrm{O}_{5}$ is one of the most promising candidates for cathodes for LIBs because of its intercalation structure, low-cost, and high energy density [59]. However, the practical application of $\mathrm{V}_{2} \mathrm{O}_{5}$ is limited by sluggish kinetics of electron and $\mathrm{Li}^{+}$ transport, resulting in low specific capacities at high rates and poor cyclability. Carbon has been introduced as a composite component to enhance electrical conductivity and prevent the vanadium dissolution. As a kind of carbon materials, graphene has attracted much attention in the field of LIBs. Especially, $\mathrm{V}_{2} \mathrm{O}_{5}$-graphene composites were investigated as cathodes for LIBs.

$\mathrm{V}_{2} \mathrm{O}_{5} \cdot \mathrm{nH}_{2} \mathrm{O}$ synthesized via a simple hydrothermal route was mechanically mixed with graphene sheets to form $\mathrm{V}_{2} \mathrm{O}_{5} \cdot \mathrm{nH}_{2} \mathrm{O}$-graphene composites [61]. The composites with a structure of $\mathrm{V}_{2} \mathrm{O}_{5} \cdot \mathrm{nH}_{2} \mathrm{O}$ ribbons on graphene sheets could deliver a reversible capacity of $190 \mathrm{~mA} \mathrm{~h} / \mathrm{g}$ after 50 cycles. The graphene-based composites involved a metastable monoclinic polymorph of $\mathrm{VO}_{2}$ also were prepared by a hydrothermal method, which delivered a high capacity of $450 \mathrm{~mA} \mathrm{~h} / \mathrm{g}$ [62]. Thermal decomposition also was used to prepare $\mathrm{V}_{2} \mathrm{O}_{5}-$ graphene composites by employing $\left(\mathrm{NH}_{4}\right)_{2} \mathrm{~V}_{2} \mathrm{O}_{6}$-graphene as precursors [63]. The composites showed a specific capacity of $178 \mathrm{~mA} \mathrm{~h} / \mathrm{g}$ after 50 cycles at a current density of $0.3 \mathrm{~A} / \mathrm{g}$. The improved performance was ascribed to the conductive network built by graphene sheets. $\mathrm{V}_{2} \mathrm{O}_{5}$-graphene composites with a discharge capacity of $202 \mathrm{~mA} \mathrm{~h} / \mathrm{g}$ after 50 cycles were synthesized by a hydrothermal route based on the hydrolysis of $\mathrm{VO}(\mathrm{O} i \mathrm{Pr})_{3}$ [64]. A modified hydrothermal method of using graphite as precursors were developed to prepare $\mathrm{V}_{2} \mathrm{O}_{5}$-graphene composites, as shown in Figure 3 [60]. The composites with structure of $\mathrm{V}_{2} \mathrm{O}_{5}$ ribbons on graphene sheets were obtained. Due to the improved conductance, $\mathrm{V}_{2} \mathrm{O}_{5}$-graphene composites showed a specific capacity of $190 \mathrm{mAh} / \mathrm{g}$ after 50 cycles. $\mathrm{V}_{2} \mathrm{O}_{5}$ with extremely stable cycling was achieved by preparing $\mathrm{V}_{2} \mathrm{O}_{5}$ /graphene composites using a facile vacuum filtration method [65]. They could deliver the capacity of $0.1 \mathrm{~A} \mathrm{~h} / \mathrm{g}$ after 100,000 cycles at a current density of $10 \mathrm{~A} / \mathrm{g}$. The improvement could be ascribed to the graphene sheets which are excellent electronic conductor and could reduce the polarization of LIBs.

$\mathrm{MnO}_{2}$-graphene composites could be used as anodes for LIBs. They could be used as cathodes as well. $\mathrm{MnO}_{2}$-graphene composites were synthesized by immersing graphene sheets into a $\mathrm{KMnO}_{4}$ aqueous solution [66]. A reversible capacity of $230 \mathrm{~mA} \mathrm{~h} / \mathrm{g}$ after 150 cycles was obtained by employing sodium alginate as a binder. When PVDF was used as a binder, a bad performance of $115 \mathrm{~mA} \mathrm{~h} / \mathrm{g}$ after 150 cycles was achieved.

\section{Other Graphene-Based Composites as Cathode Materials for LIBs}

Except above composites, there are a few graphene-based composites which could be used as cathodes for LIBs. A case in point is that $\mathrm{Ag}_{2} \mathrm{~V}_{4} \mathrm{O}_{11}$-graphene composites were prepared for LIBs [67]. The composites were fabricated by mechanical mixing of carbon fluoride, $\mathrm{Ag}_{2} \mathrm{~V}_{4} \mathrm{O}_{11}$, and graphene. The ternary composites showed a specific capacity of $480 \mathrm{mAh} / \mathrm{g}$ at a rate of $5 \mathrm{C}$. The impedance analysis demonstrated that the charge transfer resistance of composites is very low, accounting for excellent rate capability. $\mathrm{FeF}_{3}$ has drawn much attention owing to its high capacity and electrical insulating. Its property could be improved by modifying it with graphene. The composites could deliver a capacity of $200 \mathrm{~mA} \mathrm{~h} / \mathrm{g}$ after 80 cycles [68]. The properties of iron fluoride-graphene composites could be improved further by preparing $\mathrm{LiF} / \mathrm{Fe} /$ graphene composites [69]. The composites showed a high reversible capacity of $150 \mathrm{~mA} \mathrm{~h} / \mathrm{g}$ after 180 cycles.

\section{Perspectives and Challenges}

Herein, we have reviewed the preparation and application of graphene-based composites as cathode materials for LIBs. In those graphene-based composites, emphasis is given to the synthesis methods and the synergistic effects between 
graphene and cathode materials. A variety of published papers are the evidences that graphene sheets are desirable candidates for enhancing the performance of cathode materials for LIBs to meet the demands of consumers.

Graphene-based cathode materials are of so many advantages. However, more effort should be made to overcome the following challenges for the commercial application of graphene-based cathode materials. (1) The effect of graphene precursor (GO) on the morphology of cathode materials are not very clear at this moment. There are some oxygencontaining groups on GO. Published papers have demonstrated that those groups affect the crystal growth of cathode materials. However, the detailed mechanism is not clear. (2) Rational design and controllable synthesis of cathode materials are of great significance for commercial application. (3) Developing the synthesis methods of graphenebased cathode materials, with low cost and environmentallyfriendly, is very necessary for the industrial production. Although the precursor of graphene (graphite) is abundant on the earth, the common precursor of graphene is GO, needing many steps and regents to transfer from graphite. The traditional approach for the synthesis of GO needs so many chemicals, leading to a high cost and potential damage to the environment. So many interesting results have been achieved from the investigation of graphene-based cathode materials. With continuous investigation of worldwide scientists, it is believed that graphene-based cathode materials for LIBs will be used in many fields, such as personal movable tools and hybrid electric vehicles.

\section{Acknowledgments}

This project was supported by The Postdoctoral Seience Foundation of Central South University and National Natural Science Foundation of China (21103046).

\section{References}

[1] A. K. Geim and K. S. Novoselov, "The rise of graphene," Nature Materials, vol. 6, no. 3, pp. 183-191, 2007.

[2] K. S. Novoselov, A. K. Geim, S. V. Morozov et al., "Electric field in atomically thin carbon films," Science, vol. 306, no. 5696, pp. 666-669, 2004.

[3] I. Meric, M. Y. Han, A. F. Young, B. Ozyilmaz, P. Kim, and K. L. Shepard, "Current saturation in zero-bandgap, top-gated graphene field-effect transistors," Nature Nanotechnology, vol. 3, no. 11, pp. 654-659, 2008.

[4] Y. M. Lin, K. A. Jenkins, V. G. Alberto, J. P. Small, D. B. Farmer, and P. Avouris, "Operation of graphene transistors at giqahertz frequencies," Nano Letters, vol. 9, no. 1, pp. 422-426, 2009.

[5] Y. M. Lin, C. Dimitrakopoulos, K. A. Jenkins et al., "100-GHz transistors from wafer-scale epitaxial graphene," Science, vol. 327, no. 5966, p. 662, 2010.

[6] Y. Dan, Y. Lu, N. J. Kybert, Z. Luo, and A. T. C. Johnson, "Intrinsic response of graphene vapor sensors," Nano Letters, vol. 9, no. 4, pp. 1472-1475, 2009.

[7] G. Lu, L. E. Ocola, and J. Chen, "Reduced graphene oxide for room-temperature gas sensors," Nanotechnology, vol. 20, no. 22, Article ID 445502, 2009.
[8] S. Guo and S. Dong, "Graphene nanosheet: synthesis, molecular engineering, thin film, hybrids, and energy and analytical applications," Chemical Society Reviews, vol. 40, pp. 2644-2672, 2011.

[9] N. G. Shang, P. Papakonstantinou, M. McMullan et al., "Catalyst-free efficient growth, orientation and biosensing properties of multilayer graphene nanoflake films with sharp edge planes," Advanced Functional Materials, vol. 18, no. 21, pp. 3506-3514, 2008.

[10] C. Liu, Z. Yu, D. Neff, A. Zhamu, and B. Z. Jang, "Graphenebased supercapacitor with an ultrahigh energy density," Nano Letters, vol. 10, no. 12, pp. 4863-4868, 2010.

[11] E. J. Yoo, J. Kim, E. Hosono, H. S. Zhou, T. Kudo, and I. Honma, "Large reversible Li storage of graphene nanosheet families for use in rechargeable lithium ion batteries," Nano Letters, vol. 8, no. 8, pp. 2277-2282, 2008.

[12] S. M. Paek, E. Yoo, and I. Honma, "Enhanced cyclic performance and lithium storage capacity of $\mathrm{SnO}_{2}$ /graphene nanoporous electrodes with three-dimensionally delaminated flexible structure," Nano Letters, vol. 9, no. 1, pp. 72-75, 2009.

[13] M. Zhang, D. Lei, X. Yin et al., "Magnetite/graphene composites: microwave irradiation synthesis and enhanced cycling and rate performances for lithium ion batteries," Journal of Materials Chemistry, vol. 20, no. 26, pp. 5538-5543, 2010.

[14] Z. S. Wu, W. Ren, L. Wen et al., "Graphene anchored with $\mathrm{Co}_{3} \mathrm{O}_{4}$ nanoparticles as anode of lithium ion batteries with enhanced reversible capacity and cyclic performance," ACS Nano, vol. 4, no. 6, pp. 3187-3194, 2010.

[15] Y. J. Mai, D. Zhang, Y. Q. Qiao, C. D. Gu, X. L. Wang, and J. P. $\mathrm{Tu}$, "MnO/reduced graphene oxide sheet hybrid as an anode for Li-ion batteries with enhanced lithium storage performance," Journal of Power Sources, vol. 216, pp. 201-207, 2012.

[16] Y. Wang, Y. Wang, E. Hosono, K. Wang, and H. Zhou, “The design of a $\mathrm{LiFePO}_{4} /$ carbon nanocomposite with a core-shell structure and its synthesis by an in situ polymerization restriction method," Angewandte Chemie, vol. 47, no. 39, pp. 7461$7465,2008$.

[17] Y. Ding, Y. Jiang, F. Xu et al., "Preparation of nano-structured $\mathrm{LiFePO}_{4}$ /graphene composites by co-precipitation method," Electrochemistry Communications, vol. 12, no. 1, pp. 10-13, 2010.

[18] F. Y. Su, C. You, Y. B. He et al., "Flexible and planar graphene conductive additives for lithium-ion batteries," Journal of Materials Chemistry, vol. 20, pp. 9644-9650, 2010.

[19] L. Wang, H. Wang, Z. Liu et al., "A facile method of preparing mixed conducting $\mathrm{LiFePO}_{4}$ /graphene composites for lithiumion batteries," Solid State Ionics, vol. 181, no. 37-38, pp. 1685-1689, 2010.

[20] Y. Wang, Z. S. Feng, J. J. Chen, and C. Zhang, "Synthesis and electrochemical performance of $\mathrm{LiFePO}_{4}$ /graphene composites by solid-state reaction," Materials Letters, vol. 71, pp. 54-56, 2012.

[21] J. Yang, J. Wang, D. Wang et al., “3D porous $\mathrm{LiFePO}_{4} /$ graphene hybrid cathodes with enhanced performance for Li-ion batteries," Journal of Power Sources, vol. 208, pp. 340-344, 2012.

[22] Y. Tang, F. Huang, H. Bi, Z. Liu, and D. Wan, "Highly conductive three-dimensional graphene for enhancing the rate performance of $\mathrm{LiFePO}_{4}$ cathode," Journal of Power Sources, vol. 203, pp. 130-134, 2012.

[23] X. Zhou, F. Wang, Y. Zhu, and Z. Liu, "Graphene modified $\mathrm{LiFePO}_{4}$ cathode materials for high power lithium ion batteries," Journal of Materials Chemistry, vol. 21, pp. 3353-3358, 2011. 
[24] J. Z. Wang, L. Lu, M. Choucair, J. A. Stride, X. Xu, and H. K. Liu, "Sulfur-graphene composite for rechargeable lithium batteries," Journal of Power Sources, vol. 196, no. 16, pp. 7030-7034, 2011.

[25] Y. Cao, X. Li, I. A. Aksay et al., "Sandwich-type functionalized graphene sheet-sulfur nanocomposite for rechargeable lithium batteries," Physical Chemistry Chemical Physics, vol. 13, no. 17, pp. 7660-7665, 2011.

[26] H. Wang, Y. Yang, Y. Liang et al., "Graphene-wrapped sulfur particles as a rechargeable lithium-sulfur battery cathode material with high capacity and cycling stability," Nano Letters, vol. 11, pp. 2644-2647, 2011.

[27] F. Zhang, X. Zhang, Y. Dong, and L. Wang, "Facile and effective synthesis of reduced graphene oxide encapsulated sulfur via oil/water system for high performance lithium sulfur cells," Journal of Materials Chemistry, vol. 22, pp. 11452-11454, 2012.

[28] L. Ji, M. Rao, H. Zheng et al., "Graphene oxide as a sulfur immobilizer in high performance lithium/sulfur cells," Journal of the American Chemical Society, vol. 133, pp. 18522-18525, 2011.

[29] N. Li, M. Zheng, H. Lu et al., "High-rate lithium-sulfur batteries promoted by reduced graphene oxide coating," Chemical Communications, vol. 48, pp. 4106-4108, 2012.

[30] M. S. Park, J. S. Yu, K. J. Kim et al., "One-step synthesis of a sulfur-impregnated graphene cathode for lithium-sulfur batteries," Physical Chemistry Chemical Physics, vol. 14, pp. 6796-6804, 2012.

[31] B. Ding, C. Yuang, L. Shen et al., "Chemically tailoring the nanostructure of graphene nanosheets to confine sulfur for high-performance lithium-sulfur batteries," Journal of Materials Chemistry A, vol. 1, pp. 1096-1101, 2013.

[32] Y. X. Wang, L. Huang, L. C. Sun et al., "Facile synthesis of a interleaved expanded graphite-embedded sulphur nanocomposite as cathode of Li-S batteries with excellent lithium storage performance," Journal of Materials Chemistry, vol. 22, pp. 47444750, 2012.

[33] L. Yin, J. Wang, F. Lin, J. Yang, and Y. Nuli, "Polyacrylonitrile/graphene composite as a precursor to a sulfur-based cathode material for high-rate rechargeable Li-S batteries," Energy \& Environmental Science, vol. 5, pp. 6966-6972, 2012.

[34] B. Wang, K. Li, D. Su, H. Ahn, and G. Wang, "Superior electrochemical performance of sulfur/graphene nanocomposite material for high-capacity lithium-sulfur batteries," Chemistry, vol. 7, pp. 1637-1643, 2012.

[35] J. Q. Huang, X. F. Liu, Q. Zhang et al., "Entrapment of sulfur in hierarchical porous graphene for lithium-sulfur batteries with high rate performance from -40 to $60^{\circ} \mathrm{C}$," Nano Energy, vol. 2, no. 2, pp. 314-321, 2013.

[36] C. Su, X. Bu, L. Xu, J. Liu, and C. Zhang, "A novel $\mathrm{LiFePO}_{4}$ /graphene/carbon composite as a performanceimproved cathode material for lithium-ion batteries," Electrochimica Acta, vol. 64, pp. 190-195, 2012.

[37] Y. Zhang, W. Wang, P. Li, Y. Fu, and X. Ma, "A simple solvothermal route to synthesize graphene-modified $\mathrm{LiFePO}_{4}$ cathode for high power lithium ion batteries," Journal of Power Sources, vol. 210, pp. 47-53, 2012.

[38] O. Toprakci, H. A. K. Toprakci, L. Ji, Z. Lin, R. Gu, and X. J. Zhang, " $\mathrm{LiFePO}_{4}$ nanoparticles encapsulated in graphenecontaining carbon nanofibers for use as energy storage materials," Renewable Sustainable Energy, vol. 4, Article ID 013121, 10 pages, 2012.

[39] Y. Shi, S. L. Chou, J. Z. Wang et al., "Graphene wrapped $\mathrm{LiFePO}_{4} / \mathrm{C}$ composites as cathode materials for $\mathrm{Li}$-ion batteries with enhanced rate capability," Journal of Materials Chemistry, vol. 22, no. 32, pp. 16465-16470, 2012.

[40] H. Bi, F. Huang, Y. Tang et al., "Study of $\mathrm{LiFePO}_{4}$ cathode modified by graphene sheets for high-performance lithium ion batteries," Electrochimica Acta, vol. 88, pp. 414-420, 2013.

[41] H. Kim, S. W. Kim, J. Hong et al., "Graphene-based hybrid electrode material for high-power lithium-ion batteries," Journal of the Electrochemical Society, vol. 158, pp. A930-A935, 2011.

[42] Y. Yin, Y. Hu, P. Wu, H. Zhang, and C. Cai, "A grapheneamorphous $\mathrm{FePO}_{4}$ hollow nanosphere hybrid as a cathode material for lithium ion batteries," Chemical Communications, vol. 48, no. 15, pp. 2137-2139, 2012.

[43] M. M. Ren, Z. Zhou, X. P. Gao, W. X. Peng, and J. P. Wei, "Core-shell $\mathrm{Li}_{3} \mathrm{~V}_{2}\left(\mathrm{PO}_{4}\right)_{3} @ \mathrm{C}$ composites as cathode materials for lithium-ion batteries," The Journal of Physical Chemistry C, vol. 112, pp. 5689-5693, 2008.

[44] H. Liu, P. Gao, J. Fang, and G. Yang, " $\mathrm{Li}_{3} \mathrm{~V}_{2}\left(\mathrm{PO}_{4}\right)$ 3/graphene nanocomposites as cathode material for lithium ion batteries," Chemical Communications, vol. 47, no. 32, pp. 9110-9112, 2011.

[45] H. Liu, G. Yang, X. Zhang et al., "Kinetics of conventional carbon coated- $\mathrm{Li}_{3} \mathrm{~V}_{2}\left(\mathrm{PO}_{4}\right) 3$ and nanocomposite $\mathrm{Li}_{3} \mathrm{~V}_{2}\left(\mathrm{PO}_{4}\right)_{3} /$ graphene as cathode materials for lithium ion batteries," Journal of Materials Chemistry, vol. 22, pp. 11039-11047, 2012.

[46] Y. Jiang, W. Xu, D. Chen et al., "Graphene modified $\mathrm{Li}_{3} \mathrm{~V}_{2}\left(\mathrm{PO}_{4}\right)_{3}$ as a high-performance cathode material for lithium ion batteries," Electrochimica Acta, vol. 85, pp. 377-383, 2012.

[47] L. Zhang, S. Wang, D. Cai et al., " $\mathrm{Li}_{3} \mathrm{~V}_{2}\left(\mathrm{PO}_{4}\right)_{3} @ \mathrm{C} /$ graphene composite with improved cycling performance as cathode material for lithium-ion batteries," Electrochimica Acta, vol. 91, pp. 108-113, 2013.

[48] G. R. Gardiner and M. S. Islam, "Anti-site defects and ion migration in the $\mathrm{LiFe}_{0.5} \mathrm{Mn}_{0.5} \mathrm{PO}_{4}$ mixed-metal cathode material," Chemistry of Materials, vol. 22, no. 3, pp. 1242-1248, 2010.

[49] H. Wang, Y. Yang, Y. Liang et al., " $\mathrm{LiMn}_{1-x} \mathrm{Fe}_{x} \mathrm{PO}_{4}$ nanorods grown on graphene sheets for ultrahigh-rate-performance lithium ion batteries," Angewandte Chemie, vol. 50, no. 32, pp. 7364-7368, 2011.

[50] J. Zhou, J. Wang, L. Zuin et al., "Spectroscopic understanding of ultra-high rate performance for $\mathrm{LiMn}_{0.75} \mathrm{Fe}_{0.25} \mathrm{PO}_{4}$ nanorodsgraphene hybrid in lithium ion battery," Physical Chemistry Chemical Physics, vol. 14, pp. 9578-9581, 2012.

[51] V. Manev, B. Banov, A. Momchilov, and A. Nassalevska, "LiMn $\mathrm{O}_{4}$ for $4 \mathrm{~V}$ lithium-ion batteries," Journal of Power Sources, vol. 57, no. 1-2, pp. 99-103, 1995.

[52] S. M. Bak, K. W. Nam, C. W. Lee et al., "Spinel $\mathrm{LiMn}_{2} \mathrm{O}_{4} /$ reduced graphene oxide hybrid for high rate lithium ion batteries," Journal of Materials Chemistry, vol. 21, pp. 17309-17315, 2011.

[53] X. Zhao, C. M. Hayner, and H. H. Hung, "Self-assembled lithium manganese oxide nanoparticles on carbon nanotube or graphene as high-performance cathode material for lithiumion batteries," Journal of Materials Chemistry, vol. 21, pp. 1729717303, 2011

[54] H. S. Kim, S. I. Kim, and W. S. Kim, "A study on electrochemical characteristics of $\mathrm{LiCoO}_{2} / \mathrm{LiNi}_{1 / 3} \mathrm{Mn}_{1 / 3} \mathrm{Co}_{1 / 3} \mathrm{O}_{2}$ mixed cathode for Li secondary battery," Electrochimica Acta, vol. 52, pp. 14571461, 2006.

[55] K. C. Jiang, S. Xin, J. S. Lee, J. Kim, X. L. Xiao, and Y. G. Guo, "Improved kinetics of $\mathrm{LiNi}_{1 / 3} \mathrm{Mn}_{1 / 3} \mathrm{Co}_{1 / 3} \mathrm{O}_{2}$ cathode material through reduced graphene oxide networks," Physical Chemistry Chemical Physics, vol. 14, pp. 2934-2939, 2012. 
[56] C. V. Rao, A. L. M. Reddy, Y. Ishikawa, and P. M. Ajayan, " $\mathrm{LiNi}_{1 / 3} \mathrm{Co}_{1 / 3} \mathrm{Mn}_{1 / 3} \mathrm{O}_{2}$-graphene composite as a promising cathode for lithium-ion batteries," ACS Applied Materials \& Interfaces, vol. 3, pp. 2966-2972, 2011.

[57] S. Yoon, K. N. Jung, S. H. Yeon, C. S. Jin, and K. H. Shin, "Electrochemical properties of $\mathrm{LiNi}_{0.8} \mathrm{Co}_{0.15} \mathrm{Al}_{0.05} \mathrm{O}_{2}$-graphene composite as cathode materialsfor lithium-ion batteries," Journal of Electroanalytical Chemistry, vol. 683, pp. 88-93, 2012.

[58] X. Ji, K. T. Lee, and L. F. Nazar, "A highly ordered nanostructured carbon-sulphur cathode for lithium-sulphur batteries," Nature Materials, vol. 8, pp. 500-506, 2009.

[59] D. Yu, C. Chen, S. Xie et al., "Mesoporous vanadium pentoxide nanofibers with significantly enhanced $\mathrm{Li}$-ion storage properties by electrospinning," Energy \& Environmental Science, vol. 4, pp. 858-861, 2011.

[60] H. Liu and W. Yang, "Ultralong single crystalline $\mathrm{V}_{2} \mathrm{O}_{5}$ nanowire/graphene composite fabricated by a facile green approach and its lithium storage behavior," Energy \& Environmental Science, vol. 4, pp. 4000-4008, 2011.

[61] G. Du, K. H. Seng, Z. Guo et al., "Graphene- $\mathrm{V}_{2} \mathrm{O}_{5} \cdot n \mathrm{H}_{2} \mathrm{O}$ xerogel composite cathodes for lithium ion batteries ", RSC Advances, vol. 1, pp. 690-697, 2011.

[62] C. Nethravathi, B. Viswanath, J. Michael, and M. Rajamath, "Hydrothermal synthesis of a monoclinic $\mathrm{VO}_{2}$ nanotubegraphene hybrid for use as cathode material in lithium ion batteries," Carbon, vol. 50, pp. 4839-4846, 2012.

[63] Z. L. Wang, D. Xu, Y. Huang, Z. Wu, L. M. Wang, and X. B. Zhang, "Facile, mild and fast thermal-decomposition reduction of graphene oxide in air and its application in high-performance lithium batteries," Chemical Communications, vol. 48, pp. 976978, 2012.

[64] X. Rui, J. Zhu, D. Sim et al., "Reduced graphene oxide supported highly porous $\mathrm{V}_{2} \mathrm{O}_{5}$ spheres as a high-power cathode material for lithium ion batteries," Nanoscale, vol. 3, pp. 4752-4758, 2011.

[65] J. W. Lee, S. Y. Lim, H. M. Jeong, T. H. Hwang, and J. K. Kang, "Extremely stable cycling of ultra-thin $\mathrm{V}_{2} \mathrm{O}_{5}$ nanowiregraphene electrodes for lithium rechargeable battery cathodes," Energy \& Environmental Science, vol. 5, pp. 9889-9894, 2012.

[66] J. Li, Y. Zhao, N. Wang, Y. Ding, and L. Guan, "Enhanced performance of a $\mathrm{MnO}_{2}$-graphene sheet cathode for lithium ion batteries using sodium alginate as a binder," Journal of Materials Chemistry, vol. 22, pp. 13002-13004, 2012.

[67] P. Meduri, H. Chen, X. Chen et al., "Hybrid $\mathrm{CF}_{x}-\mathrm{Ag}_{2} \mathrm{~V}_{4} \mathrm{O}_{11}$ as a high-energy, power density cathode for application in an underwater acoustic microtransmitter," ElectroChemical Communications, vol. 13, pp. 1344-1348, 2011.

[68] X. Zhao, C. M. Hayner, M. C. Kung, and K. Kung, "Photothermal-assisted fabrication of iron fluoride-graphene composite paper cathodes for high-energy lithium-ion batteries," Chemical Communications, vol. 48, pp. 9909-9911, 2012.

[69] R. Ma, Y. Dong, L. Xi, S. Yang, Z. Lu, and C. Chung, "Fabrication of $\mathrm{LiF} / \mathrm{Fe} / \mathrm{Graphene}$ nanocomposites as cathode material for lithium-ion batteries," ACS Applied Materials \& Interfaces, vol. 5, no. 3, pp. 892-897, 2013. 

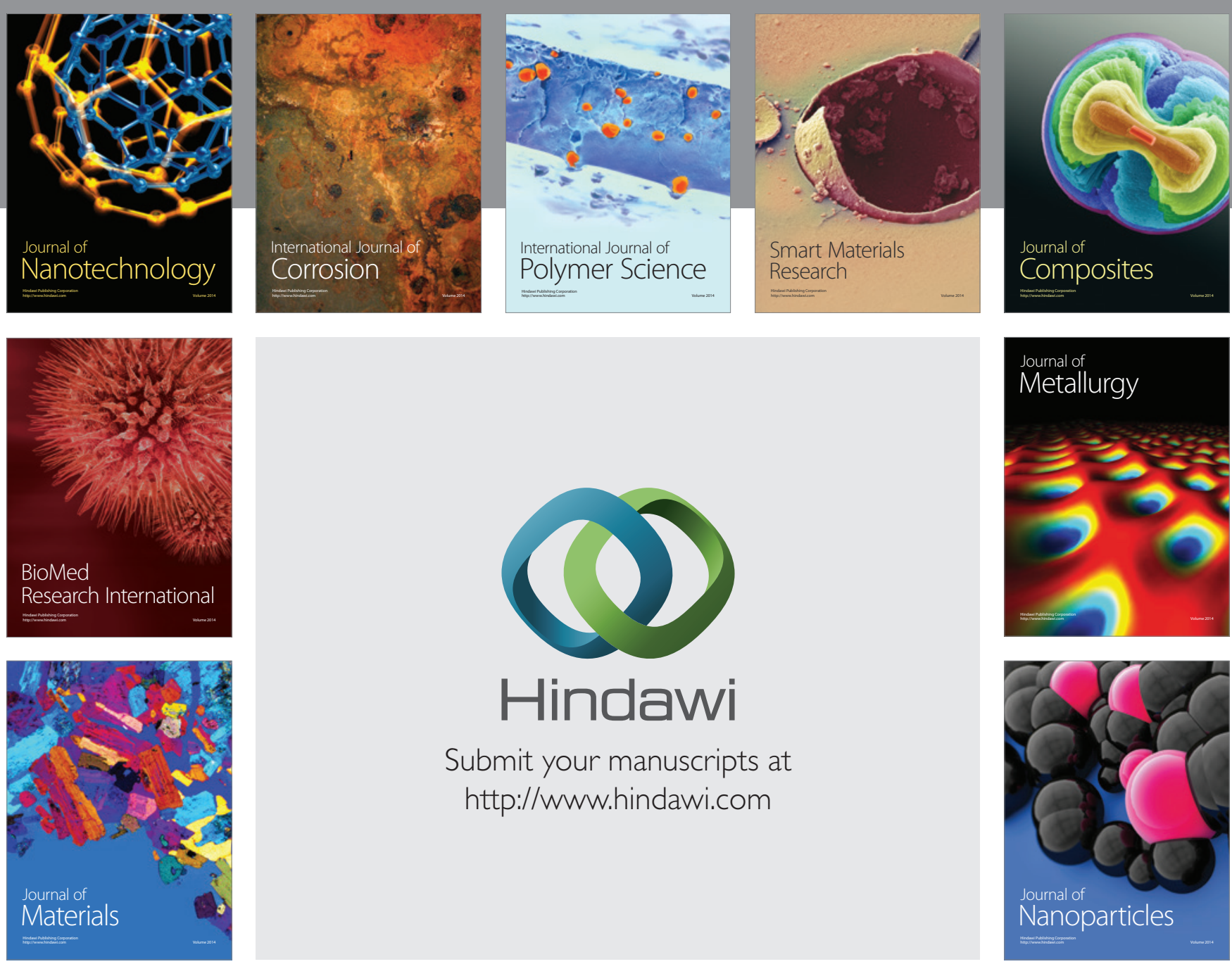

Submit your manuscripts at http://www.hindawi.com
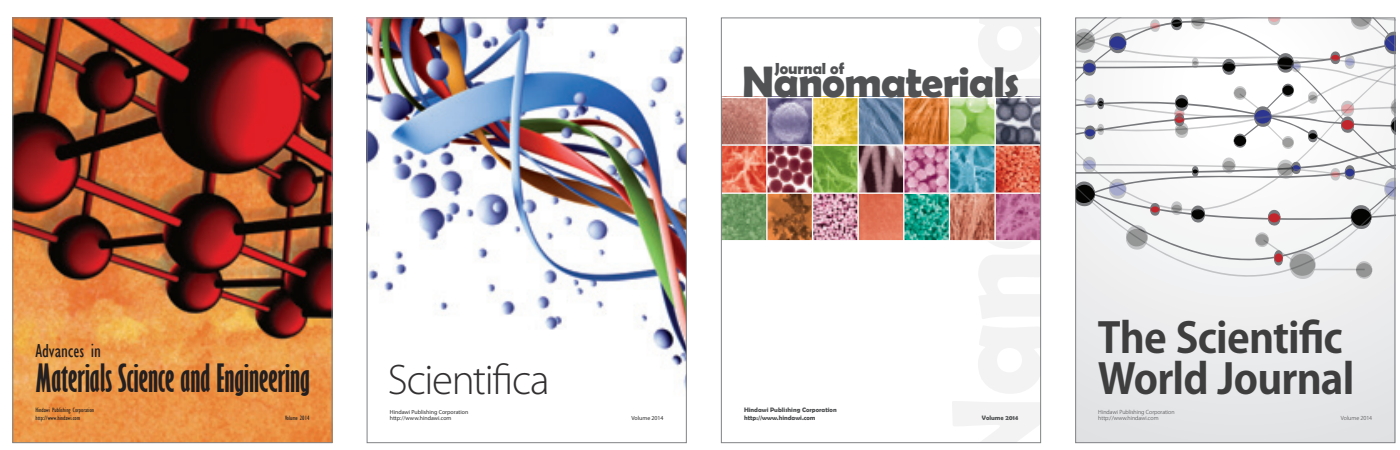

\section{The Scientific World Journal}
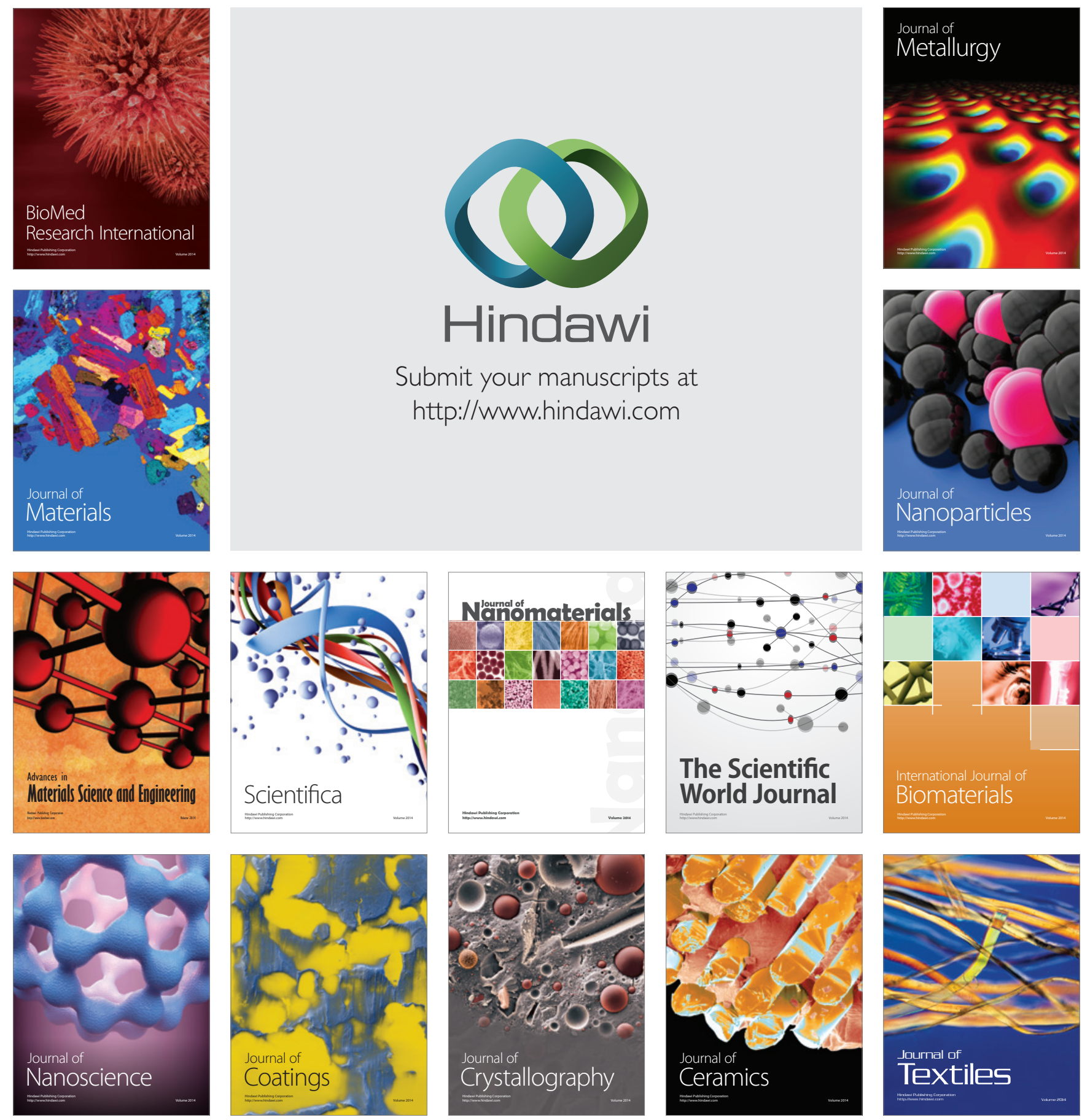